\title{
Importance and determinants of Gleason score undergrading on biopsy sample of prostate cancer in a population-based study
}

Elisabetta Rapiti $1^{*}$, Robin Schaffar ${ }^{1}$, Christophe Iselin², Raymond Miralbell ${ }^{3}$, Marie-Françoise Pelte ${ }^{4}$, Damien Weber ${ }^{3}$, Roberto Zanetti ${ }^{5}$, Isabelle Neyroud-Caspar ${ }^{1}$ and Christine Bouchardy ${ }^{1}$

\begin{abstract}
Background: In this population-based study, we investigated the degree of concordance between Gleason scores obtained from prostate biopsies and those obtained from prostatectomy specimens, as well as the determinants of biopsy understaging.

Methods: We considered for this study all 371 prostate cancer patients recorded at the Geneva Cancer Registry diagnosed from 2004 to 2006 who underwent a radical prostatectomy. We used the kappa statistic to evaluate the Gleason score concordance from biopsy and prostatectomy specimens. Logistic regression was used to determine the parameters that predict the undergrading of the Gleason score in prostate biopsies.

Results: The kappa statistic between biopsy and prostatectomy Gleason score was $0.42(p<0.0001)$, with 67\% of patients exactly matched, and $26 \%(n=95)$ patients with Gleason score underestimated by the biopsy. In a multi-adjusted model, increasing age, advanced clinical stage, having less than ten biopsy cores, and longer delay between the two procedures, were all independently associated with biopsy undergrading. In particular, the proportion of exact match increased to $72 \%$ when the patients had ten or more needle biopsy cores. The main limitation of the study is that both biopsy and prostatectomy specimens were examined by different laboratories.

Conclusions: The data show that concordance between biopsy and prostatectomy Gleason scores lies within the classic clinical standards in this population-based study. The number of biopsy cores appears to strongly impact on the concordance between biopsy and radical prostatectomy Gleason score.
\end{abstract}

Keywords: Prostate cancer, Gleason score, Biopsy, Prostatectomy, Population-based study, Biopsy undergrading

\section{Background}

The Gleason grading system, based upon architectural features of prostate cancer cells, is the most widely used histological grading method for prostatic adenocarcinoma. The Gleason score (GS) closely correlates with clinical behavior, and provides an important index of prognosis. Furthermore, this score is one of the key determinants in treatment decision making, together with stage, age and prostate-specific antigen [1]. Indeed, most models who were developed to predict the likelihood of

\footnotetext{
* Correspondence: elisabetta.rapiti@unige.ch

${ }^{1}$ Geneva Cancer Registry, Institute for Social and Preventive Medicine, University of Geneva, 55 boulevard de la Cluse, 1205 Geneva, Switzerland Full list of author information is available at the end of the article
}

pre-treatment findings with long-term outcomes, incorporate biopsy GS [1].

Significant discrepancies exist between the GS determined by the prostate biopsy, and the GS based upon the pathologic specimen. It has been observed that the GS from needle biopsies underestimates the GS of the radical prostatectomy specimen in 19 to $57 \%$ of all cases depending on the series and the periods examined [2-8]. Such downgrading has a significant impact on treatment decisions and patient outcomes, particularly when the choice of treatment is between active surveillance and curative intent therapy.

Several factors can influence the likelihood that the biopsy GS underestimates the prostatectomy score, including the PSA level, the level of pathologist expertise, the

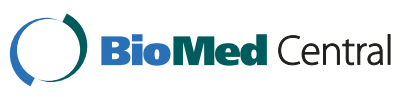


patient's age, the results of the digital rectal examination, the prostate gland volume, the percentage of cancer cells in the biopsy sample and the number of biopsies obtained [5,7,9-11]. With reference to the last issue, it is worth mentioning that the European Association of Urologists (EAU) in 2008 recommended obtaining at least 10 cores during the biopsy [12], while in the most recent guidelines reduced this number to eight [13].

In this population-based study, we investigated the degree of concordance between GSs obtained from needle biopsy of the prostate and radical prostatectomy, and we assessed the parameters that may be related to undergrading the GS in prostate biopsy.

\section{Methods}

Using data from the population-based Geneva Cancer Registry, we considered for this study all 371 prostate cancer patients diagnosed from 2004 to 2006, who underwent a radical prostatectomy.

The Geneva Cancer Registry collects information from various sources and is considered accurate, as witnessed by its very low percentage $(<2 \%)$ of cases recorded from death certificates only [14]. All hospitals, pathology laboratories, and private practitioners in the canton of Geneva are requested to report every cancer case. Trained tumor registrars systematically extract data from medical and laboratory records and physicians regularly receive enquiry forms to complete missing data.

Recorded data for each cancer case include sociodemographic variables; method of detection; prostate-specific antigen (PSA) value at diagnosis; tumor characteristics (including histology, differentiation based on tumor grade, and GS); stage at diagnosis according to both clinical and pathological TNM classification; lymph node status; treatment; survival status; and cause of death. Different laboratories, from both the public and the private sector, examine biopsy and prostatectomy specimens in Geneva. For this study, the variables of interest were age, socioeconomic status based on the patient's last occupation (high, middle, low, unknown), sector of care of the first treatment (public, private), PSA value at diagnosis $(<10 \mathrm{ng} / \mathrm{ml}$, $10-20,>20)$ and clinical stage $(\mathrm{T} 1-\mathrm{T} 2, \mathrm{~T} 3-\mathrm{T} 4, \mathrm{Tx})$. For each patient, we retrieved information on the number of biopsy cores and the volume of the prostate in cubic centimeters $\left(\mathrm{cm}^{3}\right)$. We also calculated the number of biopsy procedures performed by each operator during the study period within the study population as an indicator of the experience of the biopsy performers. To account for the possibility of a change in the severity of the disease occurring during the delay between the biopsy and the prostatectomy, we calculated the difference in days between the prostatectomy and the biopsy dates.

Concordance between biopsy and prostatectomy GSs was calculated through the kappa statistic [15]. The kappa statistic corrects for agreement expected by chance: kappa values $<0$ indicates poor agreement; 0 to $<0.20$ indicate slight agreement; 0.21 to $<0.40$ indicate fair agreement; 0.41 to $<0.60$ indicate moderate agreement; 0.61 to $<0.80$ indicate substantial agreement; and 0.81 to $\leq 1.0$ indicate almost perfect agreement [16]. We calculated kappa for the individual GS (2 to 10) and for categories of GS ( $\leq 6,7$, 8-10). Rates of undergrading of GS categories were calculated and with logistic regression we assessed determinants of GS categories undergrading. We used a casecontrol approach considering as cases those patients whose biopsy GS was lower than the prostatectomy GS, and as controls everybody else. In the multivariate analysis we used the back step procedure, entering all the variables statistically significant in univariate analysis at the same time.

All data analysis was conducted at the Geneva Cancer registry. The Registry has general registry approval by the Swiss Federal Commission of Experts for professional secrecy in medical research (Commission d'experts pour le secret professionnel en matière de recherche medical). This approval permits cancer data collection and its use for research purposes.

\section{Results}

The prostate cancer patients were on average $63( \pm 6.3)$ years old at diagnosis. For $242(65 \%)$ patients, the PSA value at diagnosis was below $10 \mathrm{ng} / \mathrm{ml}$; the clinical stage was classified as T1-T2a for $73 \%$ of patients. The median prostate volume was $36.6 \mathrm{cc}$ (range 4-166) and the median number of biopsy cores was 10 (range 2-22). Thirty percent of patients had a biopsy by a physician performing less than 10 biopsies in the three-year study period. The median delay between biopsy and prostatectomy was 84 days (range 7-412).

Figure 1 shows the concordance between biopsy and prostatectomy individual GSs. An exact match was observed for $67 \%$ of patients $(n=248)$ while for $26 \%(n=95)$ the GS was underestimated by the biopsy; in $7 \%$ of patients, it was overestimated. The kappa statistic was 0.42 , indicating a moderate agreement. When considering the categories of GS $(\leq 6,7,8-10)$ the patients understaged by the biopsy were $87(23 \%)$ while the GS matched for 267 patients $(72 \%)$. The kappa for the categories of GS was $0.48(\mathrm{p}<0.0001)$, also indicating a moderate agreement. Over 30\% of patients classified as Gleason score six or less from the biopsy, were Gleason score seven or more according to the prostatectomy.

The concordance significantly differed across categories of needle cores, number of biopsies performed by the operator and time between the biopsy and the prostatectomy. The kappa statistic for the patients who had nine or less biopsy cores was $0.35(\mathrm{p}<0.001)$ and the proportion of concordance was $62 \%$. For the patients 


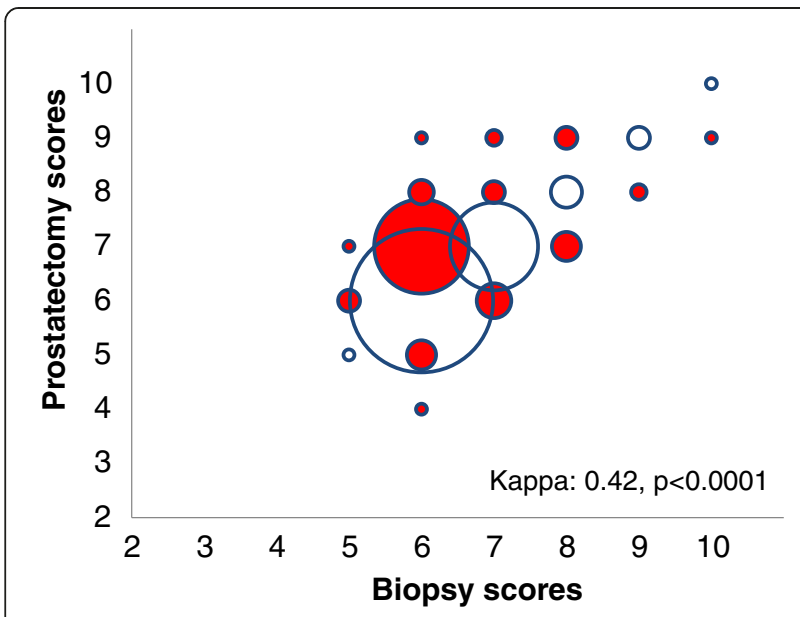

Figure 1 Concordance between biopsy and prostatectomy individual Gleason scores. Empty circles represent concordant scores between biopsy and prostatectomy; red filled circles represent discordant scores. The size is proportional to the number of cases falling in each combination.

who had 10 or more biopsy cores the kappa statistic was $0.49(\mathrm{p}<0.001)$ and the proportion of concordance increased to $72 \%$. The kappa statistic between biopsy and prostatectomy GS was $0.34(\mathrm{p}<0.001)$ for the patients who had their biopsy performed by an operator with less than 30 procedures during the study period, and 0.44 $(\mathrm{p}<0.001)$ if the operator performed 30 or more procedures. The kappa statistic for patients who had their prostatectomy within the median value (84 days, 2.7 months) from the biopsy was $0.54(\mathrm{p}<0.001)$, the statistic for the group who had a longer delay was 0.31 $(\mathrm{p}<0.001)$.

In the univariate logistic regression analysis, the variables associated with biopsy undergrading (cases $=95$ ) were age, sector of care of the first treatment, clinical stage, number of biopsy cores, prostate volume, number of procedures performed by the biopsy operator, and the delay between the biopsy and the prostatectomy (Table 1). In the multivariate analysis the variables independently associated with undergrading selected for the model were age, with a $4 \%$ increase by each extra year of age (OR: 1.04, 95\% CI: 1.00-1.09; $\mathrm{p}=0.038$ ), clinical stage (OR: T3-T4 vs. T1-T2: 1.81, 95\% CI: 1.06-3.10; $\mathrm{p}=0.030$ ), number of cores $(\mathrm{OR} \leq 9$ cores vs. $10+: 1.93,95 \% \mathrm{CI}$ : 1.16-3.22; $\mathrm{p}=0.011)$, and delay between biopsy and prostatectomy, with $1 \%$ increase by each extra day of delay between the 2 procedures (OR: 1.01, 95\% CI: 1.00-1.01, $\mathrm{p}=0.018)($ Table 1).

\section{Discussion}

This study shows that in Geneva, the concordance between the GSs of biopsy and those of prostatectomy is moderate, and lies within the current standards. Our study also confirms that a lower number of biopsy cores is an important and independent determinant of biopsy undergrading.

The finding of a $67 \%$ exact match in grading between biopsy and prostatectomy observed in Geneva is similar to the proportion found in other studies. Muntener et al. and Rajinikanth et al. both found exact match between biopsy and prostatectomy GS categories as in $69 \%$ of patients $[4,8]$. In particular the latter found that the exact match improved from $58 \%$ in $1992-1996$ to $75 \%$ in 2002-2006, which represents a period closer to our study period [8].

As reported by other authors, we found that a higher number of biopsy cores is associated with a decreased risk of undergrading $[10,17]$. In our study, the proportion of exact matching improved significantly, from $62 \%$ to $72 \%$, when the patients had ten or more cores compared with those who had nine or less, reinforcing the 2008 EAU guidelines recommendations of a minimum of ten systematic cores per biopsy [12]. However, the most recent EAU guidelines reduced to eight the minimum number of biopsy cores recommended, suggesting not to exceed twelve, with adaptations according to the prostate volume [13], with the likely intent to keep a high validity and at the same time reduce the patient's discomfort and the number of biopsy complications. Serious complications may, in fact, occur after a prostate biopsy, infection being one of the most serious ones [18].

As opposed to the report from Antunes et al. [10], we found that the effect of the number of biopsy cores on the risk of undergrading did not depend on the radical prostatectomy specimen volume in multivariate analysis.

In our study, older age and a higher clinical stage of the disease at diagnosis were also predictors of biopsy undergrading, consistently with previous investigations $[9,11,17,19,20]$. This could be linked to increasing intratumoral heterogeneity of prostate cancer among men with advanced age and advanced clinical stage, which could affect clinical estimates of the grade of malignancy [21-23].

We found that the concordance was much higher among the group of patients with a shorter delay between the biopsy and the prostatectomy $(<=84$ days, kappa $=0.54)$ than in the group with a delay longer than 84 days $(\mathrm{kappa}=0.31)$. For this reason we adjusted our multivariate model by the delay between the two procedures. Consistently with our results, Kvale et al. found that upgrading increased with increasing interval from biopsy to radical prostatectomy [17]. Delay between biopsy and surgery is more likely to have occurred in lower grade tumors and may well explain the higher discordance with the final specimen. However, a histological dedifferentiation of the tumor over time has been 
Table 1 Determinants of Gleason score undergrading between biopsy and prostatectomy

\begin{tabular}{|c|c|c|c|c|c|c|c|}
\hline & $\begin{array}{c}\text { Total } \\
(\mathrm{n}=371)\end{array}$ & $\begin{array}{l}\text { Cases } \\
(n=95)\end{array}$ & $\begin{array}{l}\text { Controls } \\
(n=276)\end{array}$ & Univariate $\mathrm{OR}^{1}(95 \% \mathrm{Cl})$ & p-value & $\begin{array}{l}\text { Multi-adjusted } \\
\mathrm{OR}^{1,2}(95 \% \mathrm{Cl})\end{array}$ & $p$-value \\
\hline Age at diagnosis years (in continuous) & & & & $1.04(1.00-1.08)$ & 0.049 & $1.04(1.00-1.09)$ & 0.038 \\
\hline \multicolumn{8}{|l|}{ Socioeconomic status } \\
\hline High & 128 & 31 & 97 & 1.00 & & & \\
\hline Middle & 155 & 43 & 112 & $1.20(0.70-2.05)$ & 0.502 & & \\
\hline Low & 82 & 20 & 62 & $1.01(0.53-1.93)$ & 0.977 & & \\
\hline Unknown & 6 & 1 & 5 & $0.63(0.07-5.56)$ & 0.674 & & \\
\hline \multicolumn{8}{|l|}{ Sector of care } \\
\hline Private & 235 & 48 & 187 & 1.00 & & & \\
\hline Public & 136 & 47 & 89 & $2.06(1.28-3.31)$ & 0.003 & & \\
\hline \multicolumn{8}{|l|}{ PSA value } \\
\hline$<10$ & 242 & 63 & 179 & 1.00 & & & \\
\hline $10-20$ & 39 & 14 & 25 & $1.59(0.78-3.25)$ & 0.203 & & \\
\hline$>20$ & 12 & 4 & 8 & $1.42(0.41-4.88)$ & 0.577 & & \\
\hline Unknown & 78 & 14 & 64 & $0.62(0.33-1.19)$ & 0.149 & & \\
\hline \multicolumn{8}{|l|}{ Clinical stage } \\
\hline $\mathrm{T} 1-\mathrm{T} 2$ & 272 & 61 & 211 & 1.00 & & 1.00 & \\
\hline T3-T4 & 93 & 33 & 60 & $1.90(1.14-3.17)$ & 0.014 & $1.81(1.06-3.10)$ & 0.030 \\
\hline Tx & 6 & 1 & 5 & $0.69(0.08-6.03)$ & 0.739 & $0.58(0.06-5.37)$ & 0.628 \\
\hline \multicolumn{8}{|l|}{ Number of biopsy cores } \\
\hline$\leq 9$ & 175 & 56 & 119 & $2.02(1.24-3.28)$ & 0.005 & $1.93(1.16-3.22)$ & 0.011 \\
\hline $10+$ & 185 & 35 & 150 & 1.00 & & 1.00 & \\
\hline Unknown & 11 & 4 & 7 & $2.45(0.68-8.83)$ & 0.171 & $2.65(0.70-10.0)$ & 0.151 \\
\hline Prostate volume $\mathrm{cm} 3$ (in continous) & & & & $0.99(0.97-1.00)$ & 0.031 & & \\
\hline \multicolumn{8}{|l|}{$\begin{array}{l}\text { Number of procedures performed by the } \\
\text { biopsy operator }\end{array}$} \\
\hline $1-29$ & 110 & 37 & 73 & $1.75(1.07-2.87)$ & 0.026 & & \\
\hline $30+$ & 254 & 57 & 197 & 1.00 & & & \\
\hline Unknown & 7 & 1 & 6 & $0.58(0.07-4.88)$ & 0.613 & & \\
\hline $\begin{array}{l}\text { Delay between biopsy and prostatectomy } \\
\text { days (in continous) }\end{array}$ & & & & $1.01(1.00-1.01)$ & 0.004 & $1.01(1.00-1.01)$ & 0.018 \\
\hline
\end{tabular}

1) OR: Odds Ratio derived from logistic regression considering as cases patients whose biopsy Gleason score was lower than the prostatectomy Gleason score and as controls everybody else, 2) Simultaneously adjusted for age, pathological stage, number of biopsy cores and delay between the two procedures.

demonstrated by some authors, but its association with disease progression is not clear [21-23].

This study has some limitations. Most importantly, both biopsy and prostatectomy specimens were examined by different laboratories, leading to possible inter-observer variability common in GS interpretation, particularly for less experienced pathologists [24]. In our study, however, two main laboratories analyzed approximately $92 \%$ of all prostate biopsies and approximately $70 \%$ of all prostate surgical samples of prostate cancer cases, which suggests a substantial experience by the examining laboratories, although we cannot rule out variability between observers. Furthermore, we found no significant difference of concordance between biopsy and prostatectomy GS by the average number of biopsy analyzed by each pathologist (data not shown).

The strength of this study is its population-based approach and that it covers a recent period of time, i.e. 2004-2005. The period chosen overlaps with a refinement of the Gleason grading system promoted in 2005 by the International Society of Urological Pathology consensus conference (ISUP) [25]. However, we estimate that this revision had a negligible impact on our results. In fact, contrary to other studies which show after the ISUP revision a tendency towards a higher Gleason prognostic due mainly to an upgrading of the secondary pattern, we did not observe any difference in the proportion of high vs. low grade cancers by year of diagnosis [26-28]. 
Similarly, we did not detect a difference in neither the primary nor the secondary Gleason pattern, for both the biopsy and the prostatectomy ( $\mathrm{p}$-value Pearson chi-square pattern 1 and pattern 2 biopsy: 0.856 and 0.663 ; pattern 1 and pattern 2 prostatectomy: 0.983 and 0.679 , respectively). Biopsy GS is an important outcome predictor of prostate cancer, and especially so for patients treated conservatively. Of particular clinical relevance is the biopsy undergrading of patients from grade seven or more to grade six or less, as these patients would move from a high/intermediate to a low risk group with a high probability of receiving a less aggressive treatment approach. In our study, there were 147 patients with T1-T2 prostate cancer stage, PSA $<10 \mathrm{ng} / \mathrm{ml}$, and a biopsy Gleason grade $<7$ who would have been ideal candidates for active surveillance. After the prostatectomy the Gleason was upgraded to a grade $>=7$ for 36 of these patients. Thus, in this population-based sample approximately $10 \%$ of patients with high-risk disease would have been undertreated. These results support the active surveillance protocols to rebiopsy patients one year after their diagnosis to reduce the proportions of understaged patients to approximately $5 \%$ [29].

\section{Conclusions}

In conclusion, this study confirms that number of biopsy cores impacts the concordance between Gleason of biopsy and prostatectomy. Several actions can be taken to optimize concordance of prostate cancer grading between needle biopsy and the prostatectomy specimen. Most importantly, adequate training of urologists in performing biopsies has the potential not only to optimize diagnostic accuracy but to minimize the patient's discomfort and morbidity as well. Extended needle biopsy protocols, with at least ten cores, improve cancer detection rates and the concordance of biopsy results with the prostatectomy findings. All pathologists evaluating prostate tissues should be systematically trained in Gleason grading. Furthermore, as recently recommended by the National Institute for Health and Clinical Excellence guidelines [1], results of all prostate biopsies should be reviewed by a urological cancer multidisciplinary team. Men who have selected active surveillance as treatment option should have a repeat biopsy after a review by this team of the risk characteristics, including life expectancy, PSA level, digital rectal examination, and prostate volume. Use of modern imaging devices, such as three dimensional ultrasound during needle biopsy, could further help to improve diagnostic accuracy prior to clinical decision making.

\section{Abbreviations}

EAU: European Association of Urology; GSs: Gleason scores; GS: Gleason score; PSA: Prostate-specific antigen.
Competing interests

All the authors declare that they have no financial competing interests.

\section{Authors' contributions}

ER participated in the conception and design, data analysis, interpretation, drafting and supervision of the manuscript. RS performed the data acquisition and statistical analysis. Cl participated in the data interpretation and revision of the manuscript. RM participated in the data interpretation and revision of the manuscript. MFP performed the data acquisition. DW made a revision of the manuscript. $\mathrm{RZ}$ made a revision of the manuscript. INC performed the data acquisition. CB participated in the conception and design, data analysis, interpretation, drafting and final approval of the version. All authors read and approved the final manuscript.

\section{Acknowledgements}

We thank Milena Uehlinger for technical and editorial assistance and the Geneva Cancer Registry team for providing data and support. We thank the members of the Geneva Prostate Cancer Research Group for their active contribution in this study.

\section{Author details}

${ }^{1}$ Geneva Cancer Registry, Institute for Social and Preventive Medicine, University of Geneva, 55 boulevard de la Cluse, 1205 Geneva, Switzerland. 2Division of Urology Surgery, Geneva University Hospitals, rue Gabrielle Perret-Gentil 4, 1211 Geneva 14, Switzerland. ${ }^{3}$ Division of Radiation Oncology, Geneva University Hospitals, avenue de la Roseraie 53, 1205 Geneva, Switzerland. ${ }^{4}$ Division of Clinical Pathology, Geneva University Hospitals, rue Michel-Servet 1, 1206 Geneva, Switzerland. ${ }^{5}$ Piedmont Cancer Registry, CPO, Torino, Italy.

Received: 6 November 2012 Accepted: 9 April 2013

Published: 11 April 2013

\section{References}

1. Graham J, Baker M, Macbeth F, Titshall V: Diagnosis and treatment of prostate cancer: summary of NICE guidance. BMJ 2008, 336:610-612.

2. Thickman D, Speers WC, Philpott PJ, Shapiro H: Effect of the number of core biopsies of the prostate on predicting Gleason score of prostate cancer. J Urol 1996, 156:110-113.

3. Moreira Leite KR, Camara-Lopes LH, Dall'oglio MF, Cury J, Antunes AA, Sanudo A, et al: Upgrading the Gleason score in extended prostate biopsy: implications for treatment choice. Int J Radiat Oncol Biol Phys 2009, 73:353-356.

4. Muntener M, Epstein Jl, Hernandez DJ, Gonzalgo ML, Mangold L,

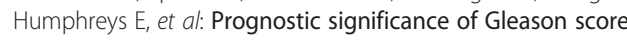
discrepancies between needle biopsy and radical prostatectomy. Eur Urol 2008, 53:767-775.

5. Pinthus JH, Witkos M, Fleshner NE, Sweet J, Evans A, Jewett MA, et al: Prostate cancers scored as Gleason 6 on prostate biopsy are frequently Gleason 7 tumors at radical prostatectomy: implication on outcome. J Urol 2006, 176:979-984.

6. Fitzsimons NJ, Presti JC Jr, Kane CJ, Terris MK, Aronson WJ, Amling CL, et al: Is biopsy Gleason score independently associated with biochemical progression following radical prostatectomy after adjusting for pathological Gleason score? J Urol 2006, 176:2453-2458.

7. Grossfeld GD, Chang JJ, Broering JM, Li JP, Lubeck DP, Flanders SC, et al: Under staging and under grading in a contemporary series of patients undergoing radical prostatectomy: results from the Cancer of the Prostate Strategic Urologic Research Endeavor database. J Urol 2001, 165:851-856.

8. Rajinikanth A, Manoharan M, Soloway CT, Civantos FJ, Soloway MS: Trends in Gleason score: concordance between biopsy and prostatectomy over 15 years. Urology 2008, 72:177-182.

9. Isariyawongse BK, Sun L, Banez LL, Robertson C, Polascik TJ, Maloney K, et al: Significant discrepancies between diagnostic and pathologic Gleason sums in prostate cancer: the predictive role of age and prostate-specific antigen. Urology 2008, 72:882-886.

10. Antunes AA, Leite KR, Dall'oglio MF, Cury J, Srougi M: The effect of the number of biopsy cores on the concordance between prostate biopsy and prostatectomy Gleason score: a prostate volume-controlled study. Arch Pathol Lab Med 2008, 132:989-992. 
11. D'Amico AV, Renshaw AA, Arsenault L, Schultz D, Richie JP: Clinical predictors of upgrading to Gleason grade 4 or 5 disease at radical prostatectomy: potential implications for patient selection for radiation and androgen suppression therapy. Int I Radiat Oncol Biol Phys 1999, 45:841-846

12. Heidenreich A, Aus G, Bolla M, Joniau S, Matveev VB, Schmid HP, et al: EAU guidelines on prostate cancer. Eur Urol 2008, 53:68-80.

13. Heidenreich A, Bellmunt J, Bolla M, Joniau S, Mason M, Matveev V, et al: EAU guidelines on prostate cancer. part 1: screening, diagnosis, and treatment of clinically localised disease. Eur Urol 2011, 59:61-71.

14. Bouchardy C, et al: Switzerland, Geneva. In Cancer Incidence in Five Continents Vol. IX. Edited by Curado MP, Edwards B, Shin HR, Storm H, Ferlay J, Heanue M. Lyon: International Agency for Research on Cancer; 2007:369-370

15. Kramer MS, Feinstein AR: Clinical biostatistics. LIV. The biostatistics of concordance. Clin Pharmacol Ther 1981, 29:111-123.

16. Landis JR, Koch GG: The measurement of observer agreement for categorical data. Biometrics 1977, 33:159-174.

17. Kvale R, Moller B, Wahlqvist R, Fossa SD, Berner A, Busch C, et al: Concordance between Gleason scores of needle biopsies and radical prostatectomy specimens: a population-based study. BJU Int 2009, 103:1647-1654.

18. Zaytoun OM, Anil T, Moussa AS, Jianbo L, Fareed K, Jones JS: Morbidity of prostate biopsy after simplified versus complex preparation protocols: assessment of risk factors. Urology 2011, 77:910-914.

19. Catalona WJ, Richie JP, Ahmann FR, Hudson MA, Scardino PT, Flanigan RC, et al: Comparison of digital rectal examination and serum prostate specific antigen in the early detection of prostate cancer: results of a multicenter clinical trial of 6,630 men. J Urol 1994, 151:1283-1290.

20. Ohori M, Wheeler TM, Dunn JK, Stamey TA, Scardino PT: The pathological features and prognosis of prostate cancer detectable with current diagnostic tests. J Urol 1994, 152:1714-1720.

21. Cumming JA, Ritchie AW, Goodman CM, Mclntyre MA, Chisholm GD: De-differentiation with time in prostate cancer and the influence of treatment on the course of the disease. Br J Urol 1990, 65:271-274.

22. Cheng L, Slezak J, Bergstralh EJ, Cheville JC, Sweat S, Zincke H, et al: Dedifferentiation in the metastatic progression of prostate carcinoma. Cancer 1999, 86:657-663.

23. Epstein Jl, Allsbrook WC Jr, Amin MB, Egevad LL: Update on the Gleason grading system for prostate cancer: results of an international consensus conference of urologic pathologists. Adv Anat Pathol 2006, 13:57-59.

24. Burchardt M, Engers R, Muller M, Burchardt T, Willers R, Epstein Jl, et al Interobserver reproducibility of Gleason grading: evaluation using prostate cancer tissue microarrays. J Cancer Res Clin Oncol 2008, 134:1071-1078.

25. Epstein Jl, Allsbrook WC Jr, Amin MB, Egevad LL: The 2005 International Society of Urological Pathology (ISUP) consensus conference on Gleason grading of prostatic carcinoma. Am J Surg Pathol 2005, 29:1228-1242.

26. Billis $A$, Guimaraes MS, Freitas LL, Meirelles L, Magna LA, Ferreira U: The impact of the 2005 international society of urological pathology consensus conference on standard Gleason grading of prostatic carcinoma in needle biopsies. J Urol 2008, 180:548-552.

27. Helpap B, Egevad L: The significance of modified Gleason grading of prostatic carcinoma in biopsy and radical prostatectomy specimens. Virchows Arch 2006, 449:622-627.

28. Egevad L, Mazzucchelli R, Montironi R: Implications of the International Society of Urological Pathology modified Gleason grading system. Arch Pathol Lab Med 2012, 136:426-434.

29. van den Bergh RC, Roemeling S, Roobol MJ, Wolters T, Schroder FH, Bangma CH: Prostate-specific antigen kinetics in clinical decision-making during active surveillance for early prostate cancer-a review. Eur Urol 2008, 54:505-516.

doi:10.1186/1471-2490-13-19

Cite this article as: Rapiti et al.: Importance and determinants of Gleason score undergrading on biopsy sample of prostate cancer in a population-based study. BMC Urology 2013 13:19.

\section{Submit your next manuscript to BioMed Central and take full advantage of:}

- Convenient online submission

- Thorough peer review

- No space constraints or color figure charges

- Immediate publication on acceptance

- Inclusion in PubMed, CAS, Scopus and Google Scholar

- Research which is freely available for redistribution

Submit your manuscript at www.biomedcentral.com/submit
Biomed Central 